\title{
Factors associated with a low prevalence of exclusive breastfeeding during hospital stay in urban and semi-rural areas of southern Vietnam
}

Quynh-Nhi Thi Le ${ }^{1,2}$, Khanh-Lam Phung $^{1}$, Van-Thuy Thi Nguyen ${ }^{1}$, Katherine L. Anders $^{3}$, Minh-Nguyet Nguyen ${ }^{1}$, Diem-Tuyet Thi Hoang ${ }^{4}$, Thuy-Tien Thi Bui', Vinh-Chau Van Nguyen ${ }^{5}$, Guy E. Thwaites', Cameron Simmons ${ }^{1,6}$ and Stephen Baker ${ }^{1,7,8^{*}}$

\begin{abstract}
Background: There is a paucity of data regarding risk factors associated with suboptimal breastfeeding practices in urbanized areas of low-middle income countries (LMICS).

Methods: Through a large prospective birth cohort, which enrolled 6706 infants in Vietnam between 2009 and 2013, we investigated the practice of exclusive breastfeeding during hospital stay in urban and semi-rural populations and aimed to identify factors associated with suboptimal breastfeeding practices. Univariate and multivariable logistic regression were performed to determine factors associated with not exclusive breastfeeding during hospital stay.
\end{abstract}

Results: Of 6076 mothers, 33\% (2187) breastfed their infant exclusively before hospital discharge; 9\% (364/4248) in urban and 74\% (1823/2458) in semi-rural areas. Exclusive breastfeeding up to 4 months was recorded in 15\% (959/ 6210) of participants; this declined to < 1\% (56/6093) at 6 months. Delivery by Caesarean section (Odds Ratio [OR] 0. 07; 95\% Confidence Interval [Cl] 0.04, 0.11 and OR 0.05; 95\% Cl 0.03, 0.08) and neonatal complications (OR 0.2; 95\% $\mathrm{Cl} 0.07,0.47$ and $\mathrm{OR} 0.25 ; 95 \% \mathrm{Cl} 0.14,0.46$ ) were common and highly significant risk factors associated with a lack of exclusive breastfeeding during hospital stay in urban and semi-rural settings, respectively.

Conclusions: To our knowledge, this is the first large-scale investigation aimed at identifying factors associated with exclusive breastfeeding during hospital stay in Vietnam. Breastfeeding promotion strategies should prioritize common risk factors in hospital, such as Caesarean section and neonatal complications, and other location specific factors associated with socioeconomics.

Keywords: Breastfeeding, Rural, Urban, Vietnam, Risk factor, C-section

\footnotetext{
* Correspondence: sbaker@oucru.org

${ }^{1}$ The Hospital for Tropical Diseases, Wellcome Trust Major Overseas

Programme, Oxford University Clinical Research Unit, Ho Chi Minh City,

Vietnam

${ }^{7}$ Centre for Tropical Medicine, Nuffield Department of Clinical Medicine,

Oxford University, Oxford, UK

Full list of author information is available at the end of the article
}

C) The Author(s). 2018 Open Access This article is distributed under the terms of the Creative Commons Attribution 4.0 International License (http://creativecommons.org/licenses/by/4.0/) which permits unrestricted use, distribution, and reproduction in any medium, provided you give appropriate credit to the original author(s) and the source, provide a link to the Creative Commons license, and indicate if changes were made. The Creative Commons Public Domain Dedication waiver (http://creativecommons.org/publicdomain/zero/1.0/) applies to the data made available in this article, unless otherwise stated. 


\section{Background}

Optimum breastfeeding is proven to be effective and cost-efficient in preventing child mortality and morbidity [1]. Vietnam has observed a substantial improvement in child nutrition in the last decade and despite breastfeeding being a common social practice in Vietnam (98\% mothers report breastfeed their children at some point [2]), it has been estimated than only $24 \%$ of Vietnamese mothers practice exclusive breastfeeding when their children are < 6 months old [3]. Infant formula is widely promoted and used in Vietnamese hospitals, with $>50 \%$ children fed infant formula during the first 3 days after birth [4]. Very few hospitals (9\%) have been accredited to the full implementation of the Baby-Friendly Hospital Initiative (BFHI), which supports exclusive breastfeeding, despite this initiative being launched in $1994[1,5,6]$.

Previous studies have shown that good breastfeeding practices in the first few months of life are associated with early and correct infant feeding after birth in the first few days and before hospital discharge [7]. Recent studies from Vietnam have measured the initiation of breastfeeding within 1 hour after birth, which is a common indicator in breastfeeding behavioural studies; the rates were: $47.5 \%$ in an urban southern area in 2000 [8], 73.6\% in a rural northern area in 2002 [9], and $90.6 \%$ in an urban central area in 2017 [10]. Notably, there were locations where children born into less affluent households were subjected to early breastfeeding more commonly than children born into more affluent households [3]. In contrast, an additional study from northern Vietnam found a higher prevalence of initiating breastfeeding within 1 hour after delivery in urban areas in comparison to rural areas [11]. This observation was explained by a higher education level of mothers from urban areas. There are little accurate data regarding breastfeeding practices in low-middle income countries (LMICs) that are undergoing economic development and urbanization, such as Vietnam [3]. It is important to further investigate differences in breastfeeding practices and associated factors between different settings in such locations.

In 2008 we initiated a birth cohort for investigating determinants of infectious diseases in urban and semi-rural infant populations in southern Vietnam [12]. Here, using data from this cohort, we aimed to assess the prevalence of various breastfeeding practices, including exclusive breastfeeding, and any breastfeeding activity during hospital stay. We further aimed to explore patterns of infant feeding during the first year of life and identify risk factors associated with inadequate breastfeeding practices during hospital stay in urban and semi-rural areas. Understanding these factors may assist in providing supporting information for promoting health strategies for expectant mothers and their infants.

\section{Methods}

\section{Study location}

Mothers residing in District 8 of Ho Chi Minh City, in Cao Lanh City and in Cao Lanh District (in Dong Thap Province) were invited to join the study. Ho Chi Minh City is the largest city in southern Vietnam with population of $7,820,000$ in 2013 and density of 3731 person/ $\mathrm{km}^{2}$ [13]. District 8 is an urban area within Ho Chi Minh City with population of $>400,000$ people and density of $>20,000$ person $/ \mathrm{km}^{2}$ [14]. Dong Thap is a semi-rural province in the Mekong Delta, located $165 \mathrm{~km}$ southwest of Ho Chi Minh City. Cao Lanh City, the provincial capital, had a population of 163,030 people and a population density of 1523 person $/ \mathrm{km}^{2}$ in $2013 ; 44.7 \%$ of the population live in a rural setting [15]. Cao Lanh District is a larger geographical area than Cao Lanh City with a population of 202,117 people and a population density of 412 person $/ \mathrm{km}^{2} ; 93.6 \%$ of the population live in a rural setting [15].

\section{Study design and participants}

This was a prospective birth cohort; the study design has been described previously [12]. Recruitment was conducted at Hung Vuong Hospital (HVH) in Ho Chi Minh City and Dong Thap Hospital (DTH) in Dong Thap Province, between 2009 and 2013 by trained study nurses who were midwives employed by these hospitals. Mothers aged > 15 years residing in either Ho Chi Minh City or Dong Thap Province for at least 12 months were invited to participate in the study at the time of hospital admission for delivery or during their antenatal visit in the 9th month of pregnancy. After providing informed consent, mothers were enrolled; infants from enrolled mothers who delivered at study hospitals were also enrolled before hospital discharge at birth.

\section{Data collection and management}

Data were collected through face-to-face interviews conducted by trained study nurses using a standardized electronic questionnaire. All study nurses were senior hospital staff with recent training (prior to conducting recruitment and interviews) in good clinical practice, standard operating procedures, and communication skills. Upon enrolment, the study nurses collected information regarding socioeconomics, obstetrics history, the characteristics of parents and infants, delivery information and current feeding practice; more detailed information can be found in the published protocol [12].

The study nurses additionally conducted routine follow up visits of enrolled infants in these hospitals at 2, 4, 6, 9, and 12 months of age. Infants in Ho Chi Minh City had additional visits at 1 and 3 months of age when they received a routine check-up and scheduled immunizations. At each follow up visit, we interviewed mothers or caregivers with questions regarding the health status of 
the infants, changes in demographic information, current feeding practice, and infectious disease. At 4, 9 and 12 months of age, blood samples $(1 \mathrm{ml})$ were collected for serological testing against various viral pathogens. Data collected at enrolment and at routine follow-up visits were stored in an encrypted web-based database. When the data collection was finalised, all data was checked and corrected for errors. Variables were derived and coded according to pre-defined definitions to produce datasets suitable for analysis.

\section{Breastfeeding data collection}

Infants were enrolled at birth and breastfeeding practices were assessed before hospital discharge using multiplechoice questions regarding whether infants were exclusively breastfed, breastfed partially, or formula-milk fed after delivery. At each routine follow up visit, breastfeeding practices were again assessed by using multiple-choice questions on whether infants were currently breastfed (within the last month), exclusively breastfed, or fed by combinations of breastmilk, formula-milk, and solid food. These current feeding practices were the self-reported behaviour that mothers provided at the interview.

\section{Main variable definitions}

Self-reported breastfeeding practices in the cohort were collected at each routine interview as (i) "exclusive breastfeeding" if receiving breast milk only, or (ii) "partial breastfeeding" if receiving breast milk in combination with other types of food, or (iii) "no breastfeeding" if not receiving breast milk. Based on reported breastfeeding practice at each interview time point, we defined variables of breastfeeding practices included (1) "exclusive breastfeeding during hospital stay", (2) "any breastfeeding during hospital stay", (3) "any breastfeeding", (4) "exclusive breastfeeding for 4 months" and (5) "exclusive breastfeeding for 6 months". Exclusive breastfeeding (1) during hospital stay was defined as baby was fed breast milk only during hospital stay, (2) "any breastfeeding during hospital stay" was defined as either exclusive or partial breastfeeding before hospital discharge after delivery, (3) "any breastfeeding" was defined as either exclusive or partial breastfeeding at any time-point from birth to the last follow-up visit. Children were considered as (4) "exclusive breastfeeding for four months" and (5) "exclusive breastfeeding for six months" if their mothers reported exclusive breastfeeding at all interviews from birth to the 4 months and 6 months follow-up visits, respectively.

The selected outcome for the main analysis was exclusive breastfeeding during hospital stay. The explanation variables were pre-defined as those that could affect breastfeeding practice at birth. These variables included socioeconomic status (household income), general characteristics of the mothers (first live child, age, education with high education meaning $>9$ years at school, occupation, ethnic group, marital status, living arrangements, complications during pregnancy, and infection with either HIV or Hepatitis B), general characteristics of the fathers (education, occupation and ethnic group), general characteristics of the infants (age at birth, sex, delivery method including Caesarean section or vaginal birth, low birthweight $(<2500 \mathrm{~g})$, premature birth with gestational age at birth $<$ 37 weeks, and neonatal complications). These variables were selected based on subject-matter knowledge and data availability. The Social Economic Status (SES) score was derived using the Demographic and Health Surveys Program using principle component analysis which was categorized into quintile levels [16].

\section{Statistical analysis}

Data generated in Ho Chi Minh City and Dong Thap were analysed separately due to differences in context and follow-up schedules. As missing data in variables of interest were low, the maximum number of missing data per variable was 11 and the number of cases with at least one missing value (\%) was $19 / 6706(<1 \%)$, we conducted a complete-case analysis. Descriptive analyses are presented by frequencies and proportions for categorical variables and medians and interquartile ranges for continuous variables. Comparisons between groups of participants were performed using the Kruskal-Wallis test for continuous variables, and Chi-squared or Fisher's exact test for categorical variables. Univariable and multivariable logistic regression were performed to determine factors associated with not initiating exclusive breastfeeding at birth. These analyses were stratified by type of data collection on diarrheal diseases (follow-up and passive data), and urban/semi-rural areas. Statistical significance was defined as a $p<0.05$; all analyses were performed using R statistical software [17].

\section{Results \\ Demographic features of the study population}

From 2009 to 2013, 7274 mothers were invited to participate this cohort study; 6743 (93\%) completed the baseline enrolment interview. Ultimately, 6706 infants from 6679 mothers were enrolled in the birth cohort. With the exception of one mother, who was interviewed 9 days after delivery, the breastfeeding practices of all mothers/infants were assessed within the first 7 days after birth and 6413/ 6706 (96\%) were assessed within 2 days of delivery. The follow-up rate was high, with 5307/6706 (79\%) infants attending all follow-up visits; 1202/6706 (18\%) infants missed several follow-up visits and 197/6706 (3\%) of infants did not attend any follow-up visits. Common causes of attrition included living too far from the study location and a reluctance of having blood drawn. In comparison to those attending all follow-up visits, infants who missed follow-up visits were more likely to live in the semi-rural 
area, be from a family with a low household income, not be the first child in the household, have parents with lower level education, have mothers without complications during pregnancy, and born by vaginal delivery (Additional file 1). The majority of infants (5778/6706, $86 \%$ ) attended the 12-month follow-up visit.

Sixty three percent (4248/6706) of participants were resident in the urban area (Ho Chi Minh City) and 37\% $(2458 / 6706)$ were resident in the semi-rural area (Dong Thap) (Table 1). Mothers in the urban area were generally of a higher social economic status (92\% (3880/ 4247) in the three highest quintiles) in comparison to mothers in the semi-rural area $(98 \%(2399 / 2455)$ in the two lowest quintiles). The majority of mothers were bearing a child for the first time (58\%; 3863/6702) and had a median age of 27 years. Almost all mothers were of Kinh ethnicity, with only $5 \%$ belonging to other minorities; most (4\%; 246/6701) minorities in the urban area were Chinese. The level of parents' education was higher in the urban area than in the semi-rural area;

Table 1 The characteristics of the study participants

\begin{tabular}{|c|c|c|c|c|c|c|}
\hline \multirow[t]{2}{*}{ Characteristic } & \multicolumn{2}{|c|}{ Total $(n=6706)$} & \multicolumn{2}{|c|}{ Urban $(n=4248)$} & \multicolumn{2}{|c|}{ Semi-rural $(n=2458)$} \\
\hline & $n$ & Frequency (\%) & $n$ & Frequency (\%) & $n$ & Frequency (\%) \\
\hline Household income & 6702 & & 4247 & & 2455 & \\
\hline 1st quintile (lowest) & & $1338(20)$ & & $47(1)$ & & $1291(53)$ \\
\hline 2nd quintile & & $1418(21)$ & & $310(7)$ & & $1108(45)$ \\
\hline 3rd quintile & & $1713(26)$ & & $1657(39)$ & & $56(2)$ \\
\hline 4th quintile & & $921(14)$ & & $921(22)$ & & $0(0)$ \\
\hline 5th quintile (highest) & & $1312(20)$ & & $1312(31)$ & & $0(0)$ \\
\hline \multicolumn{7}{|l|}{ Mother } \\
\hline Primiparous & 6702 & $3863(58)$ & 4247 & $2371(56)$ & 2455 & $1492(61)$ \\
\hline Age $^{a}$ (years) & 6702 & $27(23,31)$ & 4245 & $28(24,32)$ & 2457 & $25(21,29)$ \\
\hline Ethnic & 6701 & & 4247 & & 2454 & \\
\hline Kinh & & $6397(95)$ & & 3948 (93) & & 2449 (99) \\
\hline Chinese & & $246(4)$ & & $246(6)$ & & $0(0)$ \\
\hline Other & & $58(1)$ & & $53(1)$ & & $5(<1)$ \\
\hline High education & 6702 & $2253(34)$ & 4247 & $1692(40)$ & 2455 & $561(23)$ \\
\hline Currently married & 6702 & $6611(99)$ & 4247 & $4171(98)$ & 2455 & $2440(99)$ \\
\hline In-paid employment mother & 6702 & $4425(66)$ & 4247 & $2737(64)$ & 2455 & $1688(69)$ \\
\hline Living with others & 6699 & $6529(97)$ & 4247 & $4095(96)$ & 2452 & $2434(99)$ \\
\hline Complication during pregnancy & 6706 & $1259(19)$ & 4248 & $950(22)$ & 2458 & $309(13)$ \\
\hline HIV and/or Hepatitis B infection & 6706 & $313(5)$ & 4248 & $290(7)$ & 2458 & $23(1)$ \\
\hline \multicolumn{7}{|l|}{ Father } \\
\hline Ethnic & 6695 & & 4242 & & 2453 & \\
\hline Kinh & & $6232(93)$ & & $3784(89)$ & & $2448(99)$ \\
\hline Chinese & & $401(6)$ & & $401(9)$ & & $0(0)$ \\
\hline Other & & $62(1)$ & & $57(1)$ & & $5(<1)$ \\
\hline High education & 6696 & $2629(39)$ & 4242 & $1931(46)$ & 2454 & $698(28)$ \\
\hline In-paid employment father & 6696 & $6659(99)$ & 4242 & $4210(99)$ & 2454 & $2449(100)$ \\
\hline \multicolumn{7}{|l|}{ Infant } \\
\hline Premature at birth & 6706 & 199 (3) & 4248 & $149(4)$ & 2458 & $50(2)$ \\
\hline Male & 6706 & $3503(52)$ & 4248 & $2248(53)$ & 2458 & $1255(51)$ \\
\hline Caesarean section & 6706 & $1877(28)$ & 4248 & $1715(40)$ & 2458 & $162(7)$ \\
\hline Low birthweight & 6706 & $309(5)$ & 4248 & 199 (5) & 2458 & 110 (4) \\
\hline Neonatal complication at birth & 6706 & $275(4)$ & 4248 & $218(5)$ & 2458 & $57(2)$ \\
\hline
\end{tabular}

adescribed in median (interquartile)

High education: completed lower secondary school ( $>9$ years of education), Premature at birth: gestational age at birth $<37$ weeks, Low birthweight: birthweight $<2500 \mathrm{~g}$ 
$40 \%$ of mothers and $46 \%$ of fathers had $>9$ years of education in the urban area compared respectively to only $23 \%$ and $28 \%$ in the semi-rural area. In addition, Caesarean sections were more common in the urban area than the rural area ( $40 \%$ vs. $7 \%$, respectively). A comparable urban vs. rural trend was observed for maternal complications ( $22 \%$ vs. $13 \%)$, maternal infections ( $7 \%$ vs. $1 \%$ ), delivery before week 37 th ( $4 \%$ vs. $2 \%$ ), and infant complications at birth (5\% vs. $2 \%)$.

\section{Breastfeeding practices}

The majority of mothers (91\%; 6106/6706) fed their infants with breast milk on at least one occasion during the period in hospital for delivery; however, only a third (2187/6706) exclusively breastfed during hospital stay (Table 2). Only $15 \%(959 / 6210)$ of infants were exclusively breastfed for 4 months and $<1 \%(56 / 6093)$ were exclusively breastfed for 6 months (Table 2). Amongst the infants who were exclusively breastfed at birth and followed up to four and 6 months, the frequency of exclusive breastfeeding for four and 6 months was $49 \%(959 / 1949)$ and $3 \%(56 / 1902)$, respectively.

In both areas, the frequency of mothers reporting any breastfeeding and exclusive breastfeeding at each of the follow-up visits decreased considerably at months four and six with the introduction of solid food (Fig. 1 and Fig. 2). In addition, most mothers reported breastfeeding their infant on at least one occasion within the first year (96\%, 6222/6509 in total; 94\%, 3942/4192 in urban area; $98 \%, 2280 / 2317$ in semi-rural area).

The prevalence of exclusive breastfeeding during hospital stay was significantly lower in the urban population (9\%; 364/4248) than the semi-rural population (74\%; $1823 / 2458)(p<0.0001$, Fisher's exact test). Similarly, all other indicators of breastfeeding practices (any breastfeeding at birth, exclusive breastfeeding for four and 6 months) were significantly lower in the urban area than the semi-rural area (Table 2). Furthermore, at the final follow-up visit (12 months after delivery), 79\% (1522/ 1928) of mothers in the semi-rural area reported that they breastfed their children within the first year (Fig. 1). Correspondingly, $68 \%(2620 /, 3850)$ of mothers in the urban area reported no breastfeeding within the first year (Fig. 2 ). The use of infant formula was more common in the urban area, with a frequency of $58-93 \%$; the comparable frequency in the semi-rural area was $26-48 \%$ (Fig. 1).

\section{Factors associated with exclusive breastfeeding during hospital stay}

To explore factors associated with exclusive breastfeeding during hospital stay we stratified the cohort members by location (i.e. urban; $n=4248$ and semi-rural; $n=2458$ ) and conducted discrete analyses in these populations. Tables 3 and 4 show the results of univariate and multivariable analyses regarding explanatory factors associated with exclusive breastfeeding during hospital stay in the urban and semi-rural areas, respectively. In the urban population we found that mothers of higher socioeconomic status were more likely to not initiate exclusive breastfeeding during hospital stay in comparison to those in the lowest socioeconomic quintile (Odds Ratios [ORs] and 95\% Confidence Interval [CIs]) for the fourth and the fifth quintiles compared to the lowest quintile: $0.38 ; 95 \% \mathrm{CI}: 0.18,0.88$ and 0.29 ; 95\% CI: 0.14, 0.68 , respectively, $p<0.0001$ ). Additionally, not initiating exclusive breastfeeding during hospital stay was associated with mothers who were currently married (OR:0.23; 95\% CI 0.11, 0.50, $p<0.001$ ), complications during pregnancy (OR 0.53; 95\% CI $0.38,0.74, p<0.001$ ), mothers reporting infection during pregnancy (OR 0.53; 95\% CI 0.30, 0.87, $p=0.011$ ), mothers delivering before week 37th of gestation (OR 0.37; 95\% C: $0.15,0.81, p=$ 0.011), mothers delivering by Caesarean section (OR 0.07; $95 \%$ CI $0.04,0.11, p=0.001$ ), and those with neonatal complications at birth (OR 0.2; 95\% CI 0.07, 0.47, $p<0.001$ ).

Conversely, we found that older mothers were more likely to exclusively breastfeed their infants during hospital stay (OR of exclusive breastfeeding during hospital stay for each year of age increase: $1.04 ; 95 \%$ CI 1.01, 1.06, $p=0.003$ ). Additionally, mothers giving birth to infants with a birth weight $<2500 \mathrm{~g}$ were more likely to initiate exclusive breastfeeding during hospital stay (OR 2.02; $95 \%$ CI 1.18, 3.33, $p<0.001$ ). In the semi-rural area, we found that delivering by Caesarean section (OR 0.05; 95\% CI 0.03, 0.08, $p<0.001$ ) and the infant having neonatal complications at birth (OR 0.25; 95\% CI 0.14, $0.46, p<0.001)$ was associated with lower proportion of exclusive breastfeeding in hospital (Table 4).

Table 2 Breastfeeding practices in the urban and semi-rural areas in Vietnam

\begin{tabular}{|c|c|c|c|c|c|c|c|}
\hline \multirow[t]{2}{*}{ Breastfeeding practice } & \multicolumn{2}{|c|}{ Total $(n=6706)$} & \multicolumn{2}{|c|}{ Urban $(n=4248)$} & \multicolumn{2}{|c|}{ Semi-rural $(n=2458)$} & \multirow[t]{2}{*}{$p$ value } \\
\hline & $n$ & Frequency (\%) & $n$ & Frequency (\%) & $n$ & Frequency (\%) & \\
\hline Any breastfeeding during hospital stay & 6706 & $6106(91)$ & 4248 & $3663(86)$ & 2458 & $2443(99)$ & $<0.001$ \\
\hline Exclusive breastfeeding during hospital stay & 6706 & $2187(33)$ & 4248 & $364(9)$ & 2458 & $1823(74)$ & $<0.001$ \\
\hline Exclusive breastfeeding for 4 months & $6210^{a}$ & $959(15)$ & $4,048^{\mathrm{a}}$ & $70(2)$ & $2,162^{a}$ & $889(41)$ & $<0.001$ \\
\hline Exclusive breastfeeding for 6 months & $6093^{b}$ & $56(<1)$ & $3,983^{b}$ & $5(<1)$ & $2,110^{\mathrm{b}}$ & $51(2)$ & $<0.001$ \\
\hline
\end{tabular}

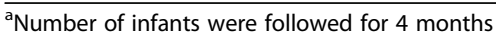

${ }^{b}$ Number of infants were followed for 6 months

All $p$ - values based on Fisher's exact test 

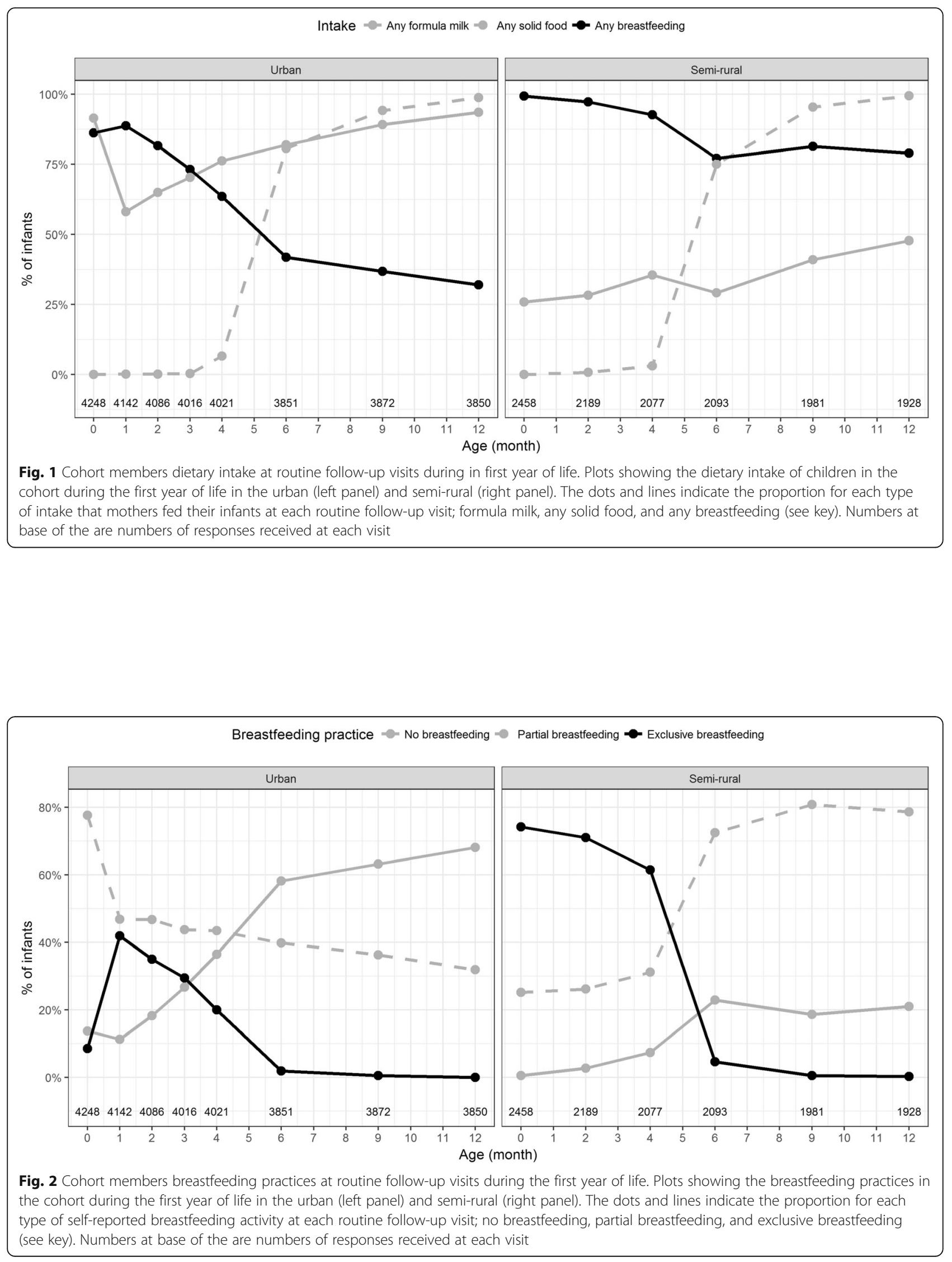
Table 3 Factors associated with exclusive breastfeeding during hospital stay in the urban population

\begin{tabular}{|c|c|c|c|c|c|c|c|c|c|c|}
\hline \multirow[t]{2}{*}{ Characteristics } & \multirow[b]{2}{*}{$n$} & \multicolumn{2}{|l|}{ Yes $(n=364)$} & \multicolumn{2}{|l|}{ No $(n=3884)$} & \multicolumn{3}{|l|}{ Unadjusted } & \multicolumn{2}{|l|}{ Adjusted } \\
\hline & & Frequency (\%) & $n$ & Frequency (\%) & OR & $(95 \% \mathrm{Cl})$ & $p$ & OR & $(95 \% \mathrm{Cl})$ & $p$ \\
\hline Household wealth (Ref: 1st quintile) & 364 & & 3883 & & & & $<0.001$ & & & $<0.001$ \\
\hline 2nd quintile & & $41(11)$ & & $269(7)$ & 0.50 & $(0.24,1.10)$ & & 0.71 & $(0.32,1.65)$ & \\
\hline 3rd quintile & & $194(53)$ & & $1463(38)$ & 0.43 & $(0.22,0.91)$ & & 0.68 & $(0.33,1.50)$ & \\
\hline 4th quintile & & $58(16)$ & & $863(22)$ & 0.22 & $(0.11,0.47)$ & & 0.38 & $(0.18,0.88)$ & \\
\hline 5th quintile & & $60(16)$ & & $1252(32)$ & 0.16 & $(0.08,0.34)$ & & 0.29 & $(0.14,0.68)$ & \\
\hline \multicolumn{11}{|l|}{ Mother } \\
\hline Primiparous & 364 & $176(48)$ & 3883 & $2195(57)$ & 0.72 & $(0.58,0.89)$ & 0.003 & 0.86 & $(0.66,1.12)$ & 0.258 \\
\hline Age $^{a}$ (years) & 364 & $28(24,32)$ & 3881 & $28(24,32)$ & 1.00 & $(0.98,1.02)$ & 0.875 & 1.04 & $(1.01,1.06)$ & 0.003 \\
\hline Ethnic (Ref: Kinh) & 364 & & 3883 & & & & 0.036 & & & 0.109 \\
\hline Chinese & & $11(3)$ & & $235(6)$ & 0.48 & $(0.25,0.85)$ & & 0.53 & $(0.26,0.98)$ & \\
\hline Other & & $5(1)$ & & $48(1)$ & 1.08 & $(0.37,2.48)$ & & 0.74 & $(0.24,1.88)$ & \\
\hline High education & 364 & $114(31)$ & 3883 & $1578(41)$ & 0.67 & $(0.53,0.84)$ & $<0.001$ & 1.09 & $(0.81,1.46)$ & 0.574 \\
\hline Currently married & 364 & $344(95)$ & 3883 & 3827 (99) & 0.25 & $(0.15,0.43)$ & $<0.001$ & 0.23 & $(0.11,0.50)$ & $<0.001$ \\
\hline In-paid employment mother & 364 & $208(57)$ & 3883 & $2529(65)$ & 0.71 & $(0.57,0.89)$ & 0.003 & 0.81 & $(0.64,1.04)$ & 0.096 \\
\hline Living with others & 364 & $344(95)$ & 3883 & $3751(97)$ & 0.61 & $(0.38,1.01)$ & 0.054 & 1.35 & $(0.70,2.84)$ & 0.386 \\
\hline Complication during pregnancy & 364 & $49(13)$ & 3884 & $901(23)$ & 0.52 & $(0.37,0.70)$ & $<0.001$ & 0.53 & $(0.38,0.74)$ & $<0.001$ \\
\hline HIV and/or Hepatitis B infection & 364 & $16(4)$ & 3884 & $274(7)$ & 0.61 & $(0.35,0.98)$ & 0.042 & 0.53 & $(0.30,0.87)$ & 0.011 \\
\hline \multicolumn{11}{|l|}{ Father } \\
\hline Ethnic (Ref: Kinh) & 363 & & 3879 & & & & 0.006 & & & 0.095 \\
\hline Chinese & & $27(7)$ & & $374(10)$ & 0.77 & $(0.50,1.14)$ & & 0.94 & $(0.60,1.44)$ & \\
\hline Other & & $12(3)$ & & $45(1)$ & 2.85 & $(1.43,5.26)$ & & 2.36 & $(1.08,4.84)$ & \\
\hline High education & 363 & $145(40)$ & 3879 & $1786(46)$ & 0.78 & $(0.63,0.97)$ & 0.025 & 1.25 & $(0.94,1.64)$ & 0.120 \\
\hline In-paid employment father & 363 & $359(99)$ & 3879 & 3851 (99) & 0.65 & $(0.25,2.21)$ & 0.451 & 0.86 & $(0.29,3.17)$ & 0.796 \\
\hline \multicolumn{11}{|l|}{ Infant } \\
\hline Premature at birth & 364 & $7(2)$ & 3884 & $142(4)$ & 0.52 & $(0.22,1.03)$ & 0.063 & 0.37 & $(0.15,0.81)$ & 0.011 \\
\hline Male & 364 & $187(51)$ & 3884 & $2061(53)$ & 0.93 & $(0.75,1.16)$ & 0.537 & 0.93 & $(0.74,1.16)$ & 0.510 \\
\hline Caesarean section & 364 & $19(5)$ & 3884 & $1696(44)$ & 0.07 & $(0.04,0.11)$ & $<0.001$ & 0.07 & $(0.04,0.11)$ & $<0.001$ \\
\hline Low birthweight & 364 & $23(6)$ & 3884 & $176(5)$ & 1.42 & $(0.89,2.18)$ & 0.140 & 2.02 & $(1.18,3.33)$ & 0.011 \\
\hline Neonatal complication at birth & 364 & $5(1)$ & 3884 & $213(5)$ & 0.24 & $(0.09,0.53)$ & $<0.001$ & 0.20 & $(0.07,0.47)$ & $<0.001$ \\
\hline
\end{tabular}

adescribed in median (interquartile)

OR: odds ratio; $95 \% \mathrm{Cl}$ : 95\% confidence interval. OR, $95 \% \mathrm{Cl}$ and $p$ values were estimated using univariable (unadjusted) and multivariable (adjusted) logistic regression models

High education: completed lower secondary school (>9 years of education), Premature at birth: gestational age at birth < 37 weeks, Low birthweight: birthweight $<2500 \mathrm{~g}$

\section{Discussion}

This was a large longitudinal prospective study conducted in urban and semi-rural areas in a transitional economic LMIC. We used data from this cohort to assess breastfeeding practices during the first year of life. Our results show a low prevalence of exclusive breastfeeding in hospitals immediately after birth, identifying differences in breastfeeding practices between regions with different socioeconomic structures [11, 18, 19]. Similar to previous cross-sectional breastfeeding studies conducted in Vietnam, this study confirmed that Vietnamese mothers generally consider breast milk as an important component of infant nutrition, with $94 \%$ and 98\% of them breastfeeding their infant on at least one occasion in the first year after birth in urban area and semi-rural area, respectively [2]. However, the prevalence of optimal breastfeeding practices in our study was low. The rate of optimal breastfeeding practices was particularly low in the urban area, with only $9 \%$ and $<1 \%$ practicing exclusive breastfeeding during hospital stay and when the child was 6 months of age, respectively. This prevalence of exclusive breastfeeding was similar to that described in a cohort study conducted in Hong Kong in 2010 [20], but was only half the prevalence measured in 
Table 4 Factors associated with exclusive breastfeeding during hospital stay in the semi-rural population

\begin{tabular}{|c|c|c|c|c|c|c|c|c|c|c|}
\hline \multirow[t]{2}{*}{ Characteristics } & \multirow[b]{2}{*}{$n$} & \multicolumn{2}{|l|}{ Yes $(n=1823)$} & \multicolumn{2}{|l|}{ No $(n=635)$} & \multicolumn{2}{|l|}{ Unadjusted } & \multirow[b]{2}{*}{$\mathrm{OR}$} & \multicolumn{2}{|l|}{ Adjusted } \\
\hline & & Frequency (\%) & $n$ & Frequency (\%) & OR & $(95 \% \mathrm{Cl})$ & p & & $(95 \% \mathrm{Cl})$ & p \\
\hline Household wealth (Ref: 1st quintile) & 1821 & & 634 & & & & 0.217 & & & 0.444 \\
\hline 2nd quintile & & $803(44)$ & & $305(48)$ & 0.85 & $(0.71,1.02)$ & & 0.94 & $(0.76,1.16)$ & \\
\hline 3rd quintile & & $42(2)$ & & $14(2)$ & 0.97 & $(0.53,1.86)$ & & 1.43 & $(0.71,3.06)$ & \\
\hline \multicolumn{11}{|l|}{ Mother } \\
\hline Primiparous & 1821 & $1085(60)$ & 634 & $407(64)$ & 0.82 & $(0.68,0.99)$ & 0.040 & 0.79 & $(0.62,1.02)$ & 0.071 \\
\hline Age $^{a}$ (years) & 1822 & $24(21,29)$ & 635 & $25(22,29)$ & 0.98 & $(0.96,1.00)$ & 0.024 & 0.99 & $(0.96,1.01)$ & 0.234 \\
\hline Ethnic: Other (Ref: Kinh) & 1820 & $4(<1)$ & 634 & $1(<1)$ & 1.39 & $(0.21,27.30)$ & 0.759 & 1.10 & $(0.16,21.69)$ & 0.929 \\
\hline High education & 1821 & $394(22)$ & 634 & $167(26)$ & 0.77 & $(0.63,0.95)$ & 0.016 & 0.91 & $(0.69,1.22)$ & 0.531 \\
\hline Currently married & 1821 & $1811(99)$ & 634 & 629 (99) & 1.44 & $(0.45,4.07)$ & 0.517 & 1.19 & $(0.05,43.13)$ & 0.920 \\
\hline In-paid employment mother & 1821 & $1238(68)$ & 634 & $450(71)$ & 0.87 & $(0.71,1.06)$ & 0.159 & 0.87 & $(0.69,1.08)$ & 0.203 \\
\hline Living with others & 1819 & $1806(99)$ & 633 & $628(99)$ & 1.11 & $(0.35,2.95)$ & 0.850 & 0.25 & $(0.01,3.56)$ & 0.359 \\
\hline Complication during pregnancy & 1823 & $212(12)$ & 635 & $97(15)$ & 0.73 & $(0.56,0.95)$ & 0.019 & 0.86 & $(0.65,1.16)$ & 0.325 \\
\hline HIV and/or Hepatitis B infection & 1823 & $14(1)$ & 635 & $9(1)$ & 0.54 & $(0.23,1.30)$ & 0.161 & 0.70 & $(0.28,1.93)$ & 0.475 \\
\hline \multicolumn{11}{|l|}{ Father } \\
\hline Ethnic: Other (Ref: Kinh) & 1820 & $3(<1)$ & 633 & $2(<1)$ & 0.52 & $(0.09,3.96)$ & 0.488 & 0.57 & $(0.09,4.75)$ & 0.570 \\
\hline High education & 1821 & $495(27)$ & 633 & $203(32)$ & 0.79 & $(0.65,0.96)$ & 0.020 & 0.96 & $(0.74,1.26)$ & 0.778 \\
\hline In-paid employment father & 1821 & $1818(100)$ & 633 & $631(100)$ & 1.92 & $(0.25,11.62)$ & 0.488 & 2.24 & $(0.29,13.85)$ & 0.402 \\
\hline \multicolumn{11}{|l|}{ Infant } \\
\hline Premature at birth & 1823 & $32(2)$ & 635 & $18(3)$ & 0.61 & $(0.35,1.12)$ & 0.109 & 0.72 & $(0.38,1.44)$ & 0.346 \\
\hline Male & 1823 & $925(51)$ & 635 & $330(52)$ & 0.95 & $(0.79,1.14)$ & 0.594 & 1.03 & $(0.85,1.26)$ & 0.744 \\
\hline Caesarean section & 1823 & $25(1)$ & 635 & $137(22)$ & 0.05 & $(0.03,0.08)$ & $<0.001$ & 0.05 & $(0.03,0.08)$ & $<0.00$ \\
\hline Low birthweight & 1823 & $75(4)$ & 635 & $35(6)$ & 0.74 & $(0.49,1.12)$ & 0.151 & 0.77 & $(0.50,1.23)$ & 0.276 \\
\hline Neonatal complication at birth & 1823 & $21(1)$ & 635 & $36(6)$ & 0.19 & $(0.11,0.33)$ & $<0.001$ & 0.25 & $(0.14,0.46)$ & $<0.00$ \\
\hline
\end{tabular}

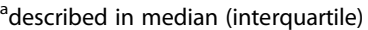

OR: odds ratio; $95 \% \mathrm{Cl}: 95 \%$ confidence interval. OR, $95 \% \mathrm{Cl}$ and $p$ values were estimated using univariable (unadjusted) and multivariable (adjusted) logistic regression models

High education: completed lower secondary school ( $>9$ years of education), Premature at birth: gestational age at birth $<37$ weeks, Low birthweight: birthweight $<2500 \mathrm{~g}$

Taiwan and the USA [21]. These findings suggest that promoting breastfeeding needs to be tailored to local populations.

The key finding from this study was that the factors associated with exclusively breastfeeding during hospital stay were different between urban and semi-rural areas. A greater number of factors were associated with exclusive breastfeeding during hospital stay in the urban population than the semi-rural population. In both areas, delivering by Caesarean section and having neonatal complications were strongly associated with not introducing exclusive breastfeeding during hospital stay. An explanation for these trends is the fact that current practice in obstetric hospitals in Vietnam is to separate mothers from their children after Caesarean sections and when the child has an infection, despite the benefits of early skin to skin contact [22].

We found a significantly lower prevalence of exclusive breastfeeding during hospital stay in the urban area $(9 \%$,
$364 / 4248)$ in comparison to the semi-rural area (74\%, 1823/2458). This figure was concordant with data from a previous cross-sectional study conducted in Hung Vuong Hospital in Ho Chi Minh City in 2014 [6], and was comparable with data originating from China regarding exclusive breastfeeding practices on hospital discharge [23]. However, a previous study from northern Vietnam, found that mothers residing in urban areas were more likely to initiate breastfeeding within 1 hour, or 1 day after birth, than women in rural areas [11]. Mothers in urban areas may correctly initiate breastfeeding within 1 hour after birth but introduce infant formula later. Our results suggest that the most common feeding practice during hospital stay in the urban area was to combine breast milk and infant formula. In the urban area, women of a higher socioeconomic status were less likely to exclusively breastfeed their infants. This difference may be linked to the capability of being able afford an alternative supplement to breast milk [9]. 
Participants in this study exhibited a similar pattern of breastfeeding behaviour to a population in northern Vietnam in which urban mothers in Hanoi with a higher socioeconomic status and undergoing Caesarean section were less likely to practice breastfeeding [11]. Here, the rate of delivery by Caesarean section was high $(28 \%$, 1877/6706), which was amplified in the urban setting (40; 1715/4248). This number was considerably higher than the range of $5-15 \%$ recommended by the World Health Organisation (WHO) [24]. However, this elevated figure was consistent with available data regarding the most common birthing practices in this location $[6,10$, $11,23]$, and in the majority of industrialized countries [25]. Potential explanations for not initiating breastfeeding in these cases are the separation of mothers and infants, a large work load for hospital staff, other priorities of healthcare professionals, and a lack of lactation consultation in large obstetric hospitals such as Hung Vuong Hospital, which has 40,000 deliveries annually [26]. Furthermore, a stressful delivery affects the initiation of breastfeeding among mothers [27], and it is perceived that antimicrobials and other drugs for the postpartum infectious have a negative impact on the benefits of breast milk [9].

Our study has limitations. As this cohort was restricted to areas with high burden of infectious diseases, this cohort may not be a population-representative sample and therefore the generalisability of our prevalence of breastfeeding practices is limited [12]. The estimated prevalence of exclusive breastfeeding for four and 6 months in the semi-rural area may be less precise than in the urban are due to differences in the number of participants recruited and in the schedules of follow up visits. Breastfeeding practices were assessed during hospital stay and follow up visits with at least one-month gap in between via interview only; therefore, these data are subject to recall bias. Investigating breastfeeding was not the primary aim of this cohort; therefore, our study criteria of exclusive breastfeeding during hospital stay, were more simplistic than those suggested by the WHO. We did not ask the time of early breastfeeding within 1 hour after birth, therefore this may induce recall bias, although time of recall was only between two and 7 days before hospital discharge. In addition, exclusive breastfeeding practices at each follow up visit were self-reported by mothers, which may lead to bias due to the different perception of the participant on the definition of exclusive breastfeeding. Nevertheless, this cohort, which used the same approach for accessing breastfeeding in this population over time [28], found that exclusive breastfeeding declines dramatically after 2 months after birth in Vietnam; identifying a specific time for the initiation of breastfeeding promotion strategies.

\section{Conclusions}

This is one of the largest studies investigating factors associated with exclusive breastfeeding during hospital stay in Vietnam. We conclude that the practice of breastfeeding in Vietnam is a national public health issue. We have identified common risk factors associated with not initiating exclusive breastfeeding during hospital stay in urban and semi-rural areas, which included having a Caesarean section and neonatal complications. Of note, the early initiation of breastfeeding after birth in Caesarean section was incorporated into formal Vietnamese health policy, as part of the implementation of the BFHI, in 2016, [5]. Even though the BFHI was launched $>20$ years ago and has been integrated into national hospital criteria since 2013, there has been no evaluation of this implementation on breastfeeding rates in Vietnam [5]. We propose future studies to investigate the most appropriate implementation strategies for improving breastfeeding in Vietnam.

\section{Additional file}

Additional file 1: Epidemiological characteristics of participants who completed all, missed several or missed all follow-up visits. (DOCX 19 kb)

\section{Abbreviations}

LMICs: low and middle-income countries; OxTREC: Oxford Tropical Research Ethics Committee; SES: Social Economic Status; WHO: World Health Organization

\section{Acknowledgements}

We thank all the cohort members and their parents/guardians for collaborating in this study. We would also like to thank the study nurses who have contributed to the study (Nguyen Thi En, Le Thi Hanh, Hoang Thi Sen, Nguyen Thi Hong Nhat, and Nguyen Thi Tuyet Hanh).

\section{Funding}

This work was funded by a Sir Henry Dale Fellow to Stephen Baker, jointly funded by the Wellcome Trust and the Royal Society (100087/Z/12/Z).

\section{Availability of data and materials}

Data that support the findings of this study are available from OUCRU Vietnam. However, restrictions apply to the availability of these data, which were used under license for the current study and are not publicly available. Data are however available from the authors upon reasonable request and with permission of OUCRU Vietnam.

\section{Authors' contributions}

CS, KLA, NTVT and NMN designed and set up the cohort study. PKL carried out the data analysis and prepared all tables and figures. HTDT and TाT were responsible for $\mathrm{HVH}$ field site. NWC was responsible for HTD site. GT was involved in general management of the study. LTQN, PKL and SB wrote the manuscript. All authors read and approved the final manuscript.

\section{Ethics approval and consent to participate}

The Oxford Tropical Research Ethics Committee (OxTREC) and the Institutional Review Boards at HTD, HVH, District 8 Hospital, Children's Hospital No.1, and DTH have provided ethical approvals. Written informed consent was obtained from parents and care-givers of infants.

Consent for publication

Not applicable.

Competing interests

The authors declare that they have no competing interests. 


\section{Publisher's Note}

Springer Nature remains neutral with regard to jurisdictional claims in published maps and institutional affiliations.

\section{Author details}

'The Hospital for Tropical Diseases, Wellcome Trust Major Overseas Programme, Oxford University Clinical Research Unit, Ho Chi Minh City, Vietnam. ${ }^{2}$ University of Medicine and Pharmacy in Ho Chi Minh City, Ho Chi Minh City, Vietnam. ${ }^{3}$ School of Biological Sciences, Monash University, Clayton, VIC, Australia. ${ }^{4}$ Hung Vuong Hospital, Ho Chi Minh City, Vietnam. ${ }^{5}$ The Hospital for Tropical Diseases, Ho Chi Minh City, Vietnam. ${ }^{6}$ Department of Microbiology and Immunology, University of Melbourne, Parkville, Australia. ${ }^{7}$ Centre for Tropical Medicine, Nuffield Department of Clinical Medicine, Oxford University, Oxford, UK. ${ }^{8}$ The Department of Medicine, University of Cambridge, Cambridge, UK.

\section{Received: 7 March 2018 Accepted: 7 October 2018}

Published online: 19 October 2018

\section{References}

1. Walters D, Horton S, Siregar AYM, Pitriyan P, Hajeebhoy N, Mathisen R, et al. The cost of not breastfeeding in Southeast Asia. Health Policy Plan. 2016;31: 1107-16.

2. Nguyen PH, Menon P, Ruel M, Hajeebhoy N. A situational review of infant and young child feeding practices and interventions in Vietnam. Asia Pac J Clin Nutr. 2011:20:359-74.

3. UNICEF. Adopting optimal feeding practices is fundamental to a child's survival, growth and development, But too few children benefit. 2015. http://data.unicef.org/nutrition/iycf.html. Accessed 15 Dec 2015.

4. Nguyen PH, Keithly SC, Nguyen NT, Nguyen TT, Tran LM, Hajeebhoy N. Prelacteal feeding practices in Vietnam: challenges and associated factors. BMC Public Health. 2013;13:932. https://doi.org/10.1186/1471-2458-13-932.

5. United Nations Children's Fund (UNICEF), World health organization, (WHO) Country experiences with the baby-friendly hospital initiative, Compendium of case studies from around the world. 2017. https://www.unicef.org/ nutrition/files/BFHI_Case_Studies_FINAL.pdf. Accessed 21 May 2018.

6. Ramoo S, Trinh TA, Hirst JE, Jeffery HE. Breastfeeding practices in a hospitalbased study of Vietnamese women. Breastfeed Med. 2014;9:479-85.

7. Murray EK, Ricketts S, Dellaport J. Hospital practices that increase breastfeeding duration: results from a population-based study. Birth. 2007;34:202-11.

8. Li L, Thi Phuong Lan D, Hoa N-T, Ushijima H. Prevalence of breastfeeding and its correlates in Ho Chi Minh City, Vietnam. Pediatr Int. 2002;44:47-54.

9. Duong DV, Binns CW, Lee AH. Breastfeeding initiation and exclusive breastfeeding in rural Vietnam. Public Health Nutr. 2004;7:795-9.

10. Nguyen PTK, Tran HT, Thai TTT, Foster K, Roberts CL, Marais BJ. Factors associated with breastfeeding intent among mothers of newborn babies in Da Nang, Viet Nam. Int Breastfeed J. 2018;13:2.

11. Thu HN, Eriksson B, Khanh TT, Petzold M, Bondjers G, Kim CNT, et al. Breastfeeding practices in urban and rural Vietnam. BMC Public Health. 2012;12:964.

12. Anders KL, Nguyen NM, Van Thuy NT, Hieu NT, Nguyen HL, Hong Tham NT, et al. A birth cohort study of viral infections in Vietnamese infants and children: study design, methods and characteristics of the cohort. BMC Public Health. 2013;13:937.

13. General Statistics Office of Vietnam. Population and Employment. 2013. http://www.gso.gov.vn/default_en.aspx?tabid=774. Accessed 18 Feb 2018.

14. General Statistics Office of HCMC. Population and Employment. 2015. http:// www.pso.hochiminhcity.gov.vn/web/guest/niengiamthongke-nam2015.

15. Government of Dong Thap Province. https://dongthap.gov.vn/wps/portal/ ctt/bdt. Accessed 18 Feb 2018.

16. Rutstein SO. Steps to constructing the new DHS Wealth Index. 6. https:// dhsprogram.com/programming/wealth\%20index/Steps_to_constructing_ the_new_DHS_Wealth_Index.pdf. Accessed 17 Dec 2015.

17. R Core Team. R: a language and environment for statistical Computing 2017. https://www.r-project.org

18. Dibley MJ, Senarath U, Agho KE. Infant and young child feeding indicators across nine east and southeast Asian countries: an analysis of National Survey Data 2000-2005. Public Health Nutr. 2010;13:1296-303.

19. World Health Organization. Infant and young child feeding data by country. The WHO global data bank on infant and young child feeding 2010. 2010. http://www.who.int/nutrition/databases/infantfeeding/countries/vnm.pdf. Accessed 19 July 2018.
20. Tarrant M, Fong DYT, Wu KM, Lee ILY, Wong EMY, Sham A, et al. Breastfeeding and weaning practices among Hong Kong mothers: a prospective study. BMC Pregnancy Childbirth. 2010;10:27.

21. Nelson JM, Li R, Perrine CG. Trends of US hospitals distributing infant formula packs to breastfeeding mothers, 2007 to 2013. Pediatrics. 2015;135:1051-6.

22. Moore ER, Bergman N, Anderson GC, Medley N. Early skin-to-skin contact for mothers and their healthy newborn infants. Cochrane Database Syst Rev. 2016;11:CD003519.

23. Qiu L, Zhao Y, Binns CW, Lee AH, Xie X. Initiation of breastfeeding and prevalence of exclusive breastfeeding at hospital discharge in urban, suburban and rural areas of Zhejiang China. Int Breastfeed J. 2009;4:1.

24. World Health Organization. Monitoring emergency obstetric care, a handbook. 2009

25. Roberts $\mathrm{CL}$, Nippita TA. International caesarean section rates: the rising tide. Lancet Glob Heal. 2015;3:e241-2.

26. Trinh AT, Roberts CL, Ampt AJ. Knowledge, attitude and experience of episiotomy use among obstetricians and midwives in Viet Nam. BMC Pregnancy Childbirth. 2015;15:101.

27. Dewey KG. Maternal and fetal stress are associated with impaired lactogenesis in humans. J Nutr. 2001;131:3012S-5S.

28. Noel-Weiss J, Boersma S, Kujawa-Myles S. Questioning current definitions for breastfeeding research. Int Breastfeed J. 2012;7:7-10.

\section{Ready to submit your research? Choose BMC and benefit from:}

- fast, convenient online submission

- thorough peer review by experienced researchers in your field

- rapid publication on acceptance

- support for research data, including large and complex data types

- gold Open Access which fosters wider collaboration and increased citations

- maximum visibility for your research: over $100 \mathrm{M}$ website views per year

At BMC, research is always in progress.

Learn more biomedcentral.com/submissions 